\title{
VALIDASI ALGORITMA ESTIMASI TOTAL SUSPENDED SOLID DAN CHL-A PADA CITRA SATELIT AQUA MODIS DAN TERRA MODIS DENGAN DATA IN SITU (Studi Kasus : Laut Utara Pulau Jawa) \\ VALIDATION OF TOTAL SUSPENDED SOLID AND CHL-A ESTIMATION ALGORITHM OF AQUA AND TERRA MODIS IMAGERY WITH IN SITU DATA (Case Study : North Part of Java Sea)
}

\author{
Loryena Ayu Karondia ${ }^{1}$, Lalu Muhamad Jaelani ${ }^{1}$ \\ ${ }^{1}$ Institut Teknologi Sepuluh Nopember , ${ }^{2}$ Institut Teknologi Sepuluh Nopember \\ Email: Imjaelany@geodesy.its.ac.id
}

\begin{abstract}
Abstrak
Total Suspended Solid (TSS) dan Chl-a merupakan beberapa parameter penentu kualitas air. Konsentrasi Total Suspended Solid yang tinggi dan konsentrasi Chl-a yang sedikit mengganggu proses fotosintesis perairan, kehidupan biota laut, dan pada pertumbuhan populasi fitoplankton yang membentuk dasar dari rantai makanan laut dan merupakan sumber utama oksigen atmosfer. Beberapa metode dapat digunakan untuk memantau perubahan persebaran TSS dan Chl-a yang terjadi di wilayah tersebut, salah satunya menggunakan teknologi penginderaan jauh. Metode penginderaan jauh merupakan metode akuisisi data menggunakan satelit. Didalam metode penginderaan jauh tersebut, dibutuhkan algoritma-algoritma estimasi TSS dan Chl-a yang akurat dalam mengestimasi nilai TSS dan Chl-a. Satelit penginderaan jauh yang digunakan adalah Satelit Aqua Modis dan Sateit Terra Modis. Penelitian ini dilakukan untuk validasi beberapa algoritma yang telah ada dengan data in situ. Algoritma yang divalidasi dalam penelitian ini adalah agoritma yang telah tersedia di dalam perangkat lunak Seadas. Dari hasil penelitian ini, didapat bahwa algoritma yang tersedia di dalam perangkat lunak Seadas belum akurat untuk melakukan perhitungan estimasi TSS dan Chl-a.
\end{abstract}

Kata kunci : Algoritma, Chl-a, Total Suspended Solid (TSS), Validasi

\begin{abstract}
Total Suspended Solid (TSS) and Chl-a is some of parameters determining the quality of water bodies. High concentration of Total Suspended Solid and low concentration of Chl-a disturbs photosynthesis process in waters, marine life, and the population growth of phytoplankton that form the base of the marine food chain and as a major source of atmospheric oxygen.Several methods can be used to monitor changes in the distribution of TSS and Chl-a which happening in the region, one of them is by using remote sensing technology. The remote sensing method requires estimation algorithms of TSS and Chl-a which can properly estimate the TSS and Chl-a thoroughly. The remote sensing satellite which is used is the Satellite Aqua Modis and Satellite Terra Modis. The intent of this study was to validate some of the algorithms that have been there before, that in this case is the validation done at some in situ points which are in the Northern Sea of Java Island. The algorithms validated in this study are the algorithms which already available in Seadas software. From the result of this research, where data validation is done on the Madura Strait, it is obtained that the available algorithms in software Seadas are not good enough to perform estimation calculations of TSS and Chl-a.
\end{abstract}

Keyword : Algorithms, Chl-a, Total Suspended Solid (TSS), Validation

\section{PENDAHULUAN}

\section{Latar Belakang}

Laut Jawa selalu menerima pencemaran dari sungai-sungai dari Jawa, Sumatera dan
Kalimantan. Di Jawa, pencemaran dipengaruhi oleh pencemaran akibat pemukiman perkotaan serta industri (World Bank, 1989) dan pemukiman domestik dan pertanian (Talaue-McManus, 2000). Tingkat pencemaran laut ini telah menjadi 
ancaman serius bagi laut Indonesia dengan segala potensinya. Komponen-komponen yang menyebabkan pencemaran laut seperti partikel kimia, limbah industri, limbah pertambangan, limbah pertanian dan perumahan, kebisingan, atau penyebaran organisme invasif (asing) di dalam laut yang berpotensi memberi efek buruk terhadap kestabilan ekosistem perairan Laut Utara Pulau Jawa.

Total Suspended Solid (TSS) dan Chl-a merupakan beberapa parameter penentu kualitas badan air. TSS merupakan zat-zat padat yang berada dalam suspensi, yang dapat dibedakan menurut ukurannya sebagai partikel tersuspensi koloid (partikel koloid) dan partikel tersuspensi biasa (partikel tersuspensi).

dalam penginderaan jauh, menjadikan pelaksanaan pemetaan sebaran TSS dan Chl-a menjadi efisien. Sudah banyak aplikasi penginderaan jauh yang digunakan untuk pemantauan aktifitas lingkungan perairan. Dengan demikian, penginderaan jauh, telah memberikan kontribusi yang signifikan dalam proses pemahaman kondisi oseanografi. Metode penginderaan jauh ini memanfaatkan citra satelit Modis untuk mengidentifikasi kualitas perairan. Dalam penelitian ini, digunakan citra satelit Aqua Modis dan Terra Modis Tahun 2014, untuk memetakan kondisi perairan.

\section{METODOLOGI PENELITIAN}

\section{Data Dan Peralatan}

- Data

Data yang digunakan dalam penelitian ini adalah:

1. Citra Satelit Aqua Modis dan Terra Modis Tahun 2014

2. Peta Vektor Pulau Jawa

3. Data sampel air Perairan Selat Madura

\section{- Peralatan}

Peralatan yang digunakan dalam penelitian ini adalah:

a. Perangkat Keras
i. GPS Handheld
ii. Kamera
Digital
untuk
dokumentasi
iii. FieldSpec

b. Perangkat Lunak
i. Sistem operasi Windows 7
ii. Ubuntu 14.04
iii. ArcGIS 10.0
iv. SeaDAS 7.1
v. Visat 5.0

c. Peralatan Uji Data Sampel Air

\section{i. Kertas Saring}

- Whatman Grade 934 AH dengan Particle Retention berukuran 1,5 $\mu \mathrm{m} \quad$ (Standard for TSS in water analysis)

- Gelman type A/E, dengan Particle Retention berukuran 1,0 $\mu \mathrm{m}$ (Standard Filter For TSS/TDS testing in sanitary water analysis procedures)

- E-D Scientific Specialities grade 161 (VWR brand grade 161) dengan Particle Retention berukuran $1,1 \mu \mathrm{m}$ (Recomended for use in TSS/TDS testing in water and wastewater)

ii. Peralatan Uji

- Desikator

- Oven dengan operasi suhu $103 \div \mathrm{C}-105 \div \mathrm{C}$

- Timbangan analitik dengan ketelitian 0,1mg

- Pengaduk magnetik

- Pipet Volume

- Gelas Ukur

- Cawan Alumunium

- Cawan Porselen

- Penjepit

- Kava Arloji

- Pompa Vacum

\section{Lokasi Penelitian}

Lokasi penelitian tugas akhir ini adalah Laut yang terletak di utara Pulau Jawa. Dimana Laut Jawa sendiri memiliki batasan koordinat $5^{\circ} 16^{\prime} 00^{\prime \prime}$ LS $111^{\circ} 43^{\prime} 52^{\prime \prime}$ BT. Data in situ yang digunakan dalam penelitian ini adalah sampel air yang diambil pada perairan Selat Madura dengan jarak minimal $1 \mathrm{~km}$ dari daratan. 


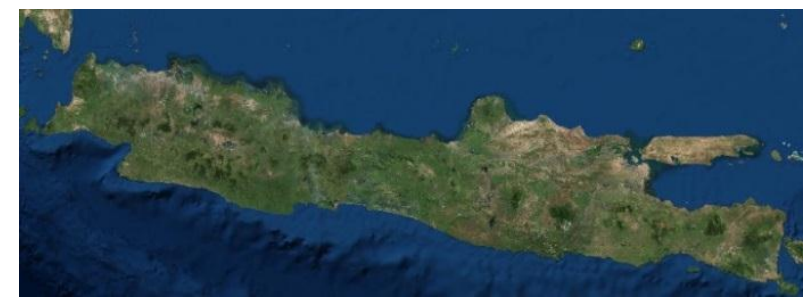

Gambar 1. Lokasi Penelitian

(tanahair.indonesia.go.id)

\section{Metode Penelitian}

Tahapan Penelitian dalam penelitian Tugas Akhir ini adalah :

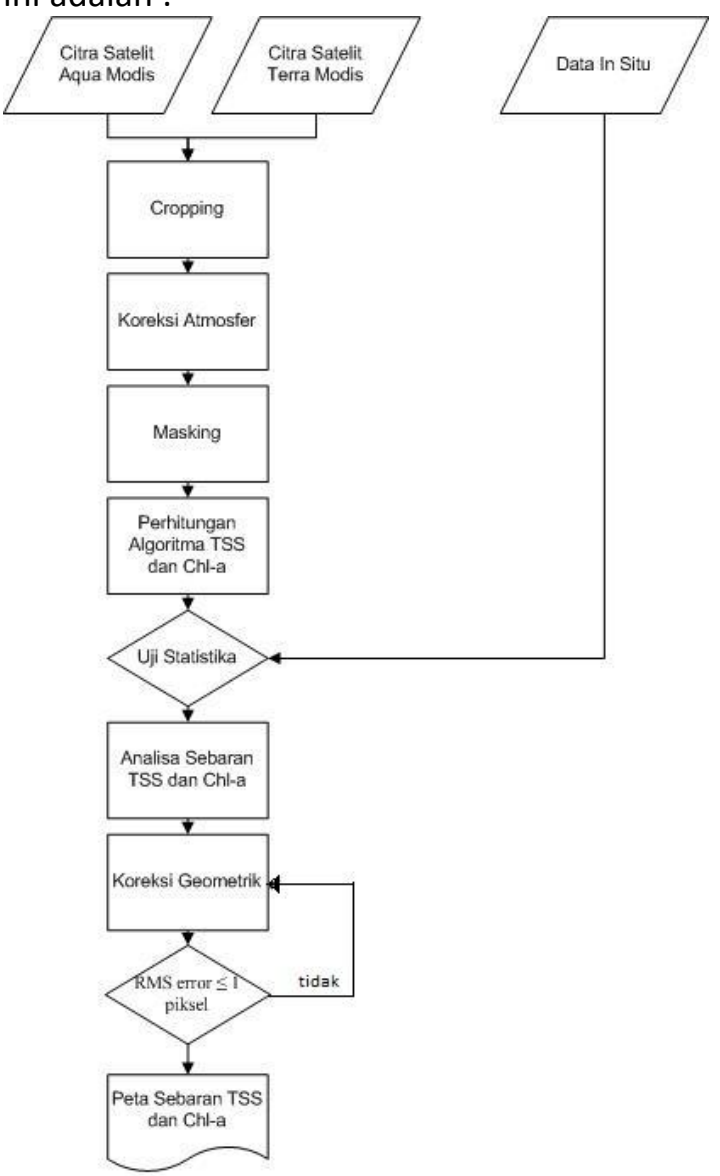

Gambar 2. Diagram Pengolahan Data

\section{HASIL DAN PEMBAHASAN}

Dalam penelitian ini menggunakan beberapa data in situ baik melalui pengukuran lapangan maupun pengunduhan data pengukuran yang dilakukan oleh orang lain pada tahun-tahun sebelumnya. Berikut kumpulan data yang digunakan
Tabel 1. Data in situ hasil pengukuran lapangan pada area Selat Madura pada 24 Maret 2015 dan 26 Maret 2014

\begin{tabular}{rrrrr}
\hline Stasiun & Lintang & \multicolumn{1}{l}{ Bujur } & TSS (g/L) & Klorofil (mg/L) \\
\hline 1 & 704337 & 9193046 & 24 & 0,532 \\
2 & 703323 & 9196945 & 42 & 0,812 \\
3 & 701568 & 9199269 & 74 & 1,094 \\
4 & 702649 & 9200424 & 27 & 0,471 \\
5 & 699994 & 9200567 & 16 & 0,421 \\
6 & 706385 & 9195644 & 15 & 0,295 \\
7 & 701357 & 9201597 & 14 & 0,368 \\
8 & 704114 & 9199646 & 20 & 0,327 \\
9 & 704384 & 9195010 & 9 & 0,236 \\
10 & 703355 & 9198889 & 9 & 0,228 \\
11 & 699700 & 9202008 & 10 & 0,262 \\
12 & 706292 & 9192318 & 40 & 0,694 \\
13 & 706088 & 9194229 & 56 & 0,874 \\
14 & 706024 & 9197009 & 8 & 0,211 \\
15 & 705283 & 9198413 & 4 & 0,105 \\
\hline
\end{tabular}

Dari proses perhitungan beberapa algoritma pada citra Aqua Modis, didapat hasil sebagai berikut.

Tabel 2. Hasil Perhitungan Algoritma Chl-a terhadap Data In situ

\begin{tabular}{|c|c|c|c|c|}
\hline \multirow[t]{2}{*}{ Stasiun } & \multicolumn{3}{|c|}{ Hasil Perhitungan Algoritma } & \multirow{2}{*}{$\begin{array}{l}\text { Data In situ } \\
\text { (mg/L) }\end{array}$} \\
\hline & Chl a & Chl oc2 & Chl oc3 & \\
\hline 4 & 20,26 & 20,040 & 20,265 & 0,471 \\
\hline 7 & 12,48 & 11,671 & 12,483 & 0,368 \\
\hline 8 & 113,1 & 215,66 & 113,1 & 0,327 \\
\hline 14 & $\mathrm{NaN}$ & $\mathrm{NaN}$ & $\mathrm{NaN}$ & 0,211 \\
\hline
\end{tabular}

(Sumber : Debby Marzella)

Tabel 3. Hasil Perhitungan Algoritma Chl-a terhadap Data In situ

\begin{tabular}{|c|c|c|c|}
\hline \multirow[t]{2}{*}{ Stasiun } & \multicolumn{2}{|c|}{$\begin{array}{l}\text { Hasil Perhitungan } \\
\text { Algoritma }\end{array}$} & \multirow{2}{*}{$\begin{array}{c}\text { Data In } \\
\operatorname{situ}(\mathrm{mg} / \mathrm{L})\end{array}$} \\
\hline & Chl giop & Chl gsm & \\
\hline 4 & 118,781 & 29,8113 & 0,471 \\
\hline 7 & $\mathrm{NaN}$ & 29,7999 & 0,368 \\
\hline 8 & 58,3173 & $\mathrm{NaN}$ & 0,327 \\
\hline 14 & 27,8111 & $\mathrm{NaN}$ & 0,211 \\
\hline
\end{tabular}

Dalam proses validasi dalam penelitian ini menggunakan data in situ Selat Madura pada 
tanggal 24 Maret 2014. Terdapat 15 titik data in situ yang digunakan untuk proses validasi, namun dikarenakan citra satelit yang banyak tertutup oleh awan, maka titik yang dapat di validasi hanya berkisar 7 titik.

Terdapat perbedaan yang sangat mencolok antara perhitungan algoritma yang dijalankan oleh perangkat lunak seaDAS dengan hasil pengukuran data in situ.

Hal tersebut dapat ditunjukkan pada grafik sebagai berikut.

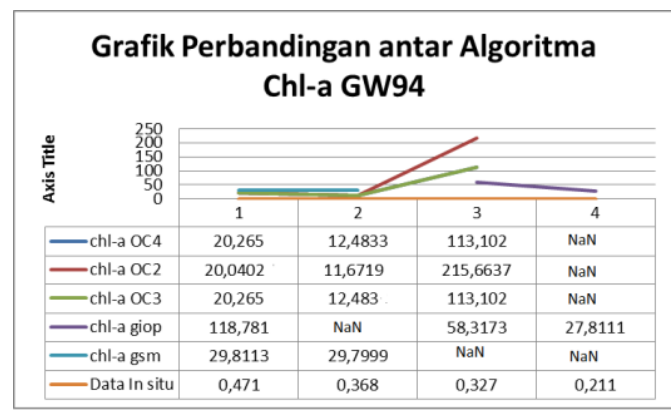

Gambar 3. Grafik Perbandingan antar Algoritma Chl-a terhadap Data In situ

Berikut adalah hasil perhitungan algoritma estimasi TSS yang menggunakan algoritma TSM Clark terhadap data in situ.

Tabel 4. Hasil Perhitungan Algoritma TSM Clark terhadap data In situ.

$\begin{array}{lll}\text { Stasiun } & \text { TSMclark Data In situ (g/L) }\end{array}$

\begin{tabular}{ccc}
\hline 4 & 2,1654 & 27 \\
7 & 2,423 & 20 \\
8 & 4,574 & 9 \\
\hline
\end{tabular}

(Sumber : Debby Marzella)

Terdapat perbedaan yang sangat mencolok antara perhitungan algoritma yang dijalankan oleh perangkat lunak seaDAS dengan hasil pengukuran data in situ. Hal tersebut dapat ditunjukkan pada grafik sebagai berikut.

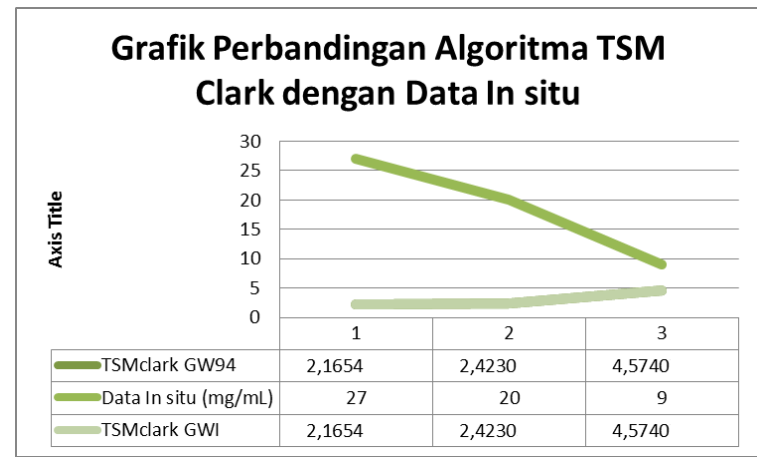

Gambar 4. Grafik Perbandingan antar Algoritma TSM Clark terhadap Data In situ

Dari proses perhitungan beberapa algoritma pada citra Terra Modis, didapat hasil sebagai berikut.

Tabel 5. Hasil Perhitungan Algoritma Chl-a terhadap Data In situ

\begin{tabular}{cccc}
\hline Stasiun & chlor-a & chl-a OC2 & Data In situ (g/L) \\
\hline 4 & 24,7944 & 50,9642 & 0,471 \\
6 & $\mathrm{NaN}$ & $\mathrm{NaN}$ & 0,295 \\
8 & 40,8356 & $\mathrm{NaN}$ & 0,327 \\
12 & 46,776 & $\mathrm{NaN}$ & 0,694 \\
13 & $\mathrm{NaN}$ & $\mathrm{NaN}$ & 0,874 \\
14 & $\mathrm{NaN}$ & $\mathrm{NaN}$ & 0,211 \\
15 & $\mathrm{NaN}$ & $\mathrm{NaN}$ & 0,105 \\
\hline
\end{tabular}

(Sumber : Debby Marzella)

Tabel 6. Hasil Perhitungan Algoritma Chl-a terhadap Data In situ

\begin{tabular}{ccclc}
\hline Stasiun & chl-a OC3 & chl giop & chl-a gsm & $\begin{array}{c}\text { Data In } \\
\text { situ (g/L) }\end{array}$ \\
\hline 4 & 24,7944 & $-28,6555$ & $\mathrm{NaN}$ & 0,471 \\
6 & $\mathrm{NaN}$ & $1,19 \mathrm{E}+07$ & $\mathrm{NaN}$ & 0,295 \\
8 & 40,8357 & $-85,8576$ & $\mathrm{NaN}$ & 0,327 \\
12 & 46,7761 & -901471 & $\mathrm{NaN}$ & 0,694 \\
13 & $\mathrm{NaN}$ & 1236104 & $\mathrm{NaN}$ & 0,874 \\
14 & $\mathrm{NaN}$ & $2,04 \mathrm{E}+07$ & $\mathrm{NaN}$ & 0,211 \\
15 & $\mathrm{NaN}$ & $2,60 \mathrm{E}+07$ & $\mathrm{NaN}$ & 0,105 \\
\hline
\end{tabular}

(Sumber : Debby Marzella)

Dari tabel diatas, nilai NaN merupakan hasil perhitungan algoritma yang diartikan tidak bernilai. Hal tersebut dapat terjadi dikarenakan perbedaan penetrasi terhadap awan ataupun distorsi lain pada tiap algoritma.

Terdapat perbedaan yang sangat mencolok antara perhitungan algoritma yang dijalankan oleh 
perangkat lunak seaDAS dengan hasil pengukuran data in situ. Hal tersebut dapat ditunjukkan pada grafik sebagai berikut.

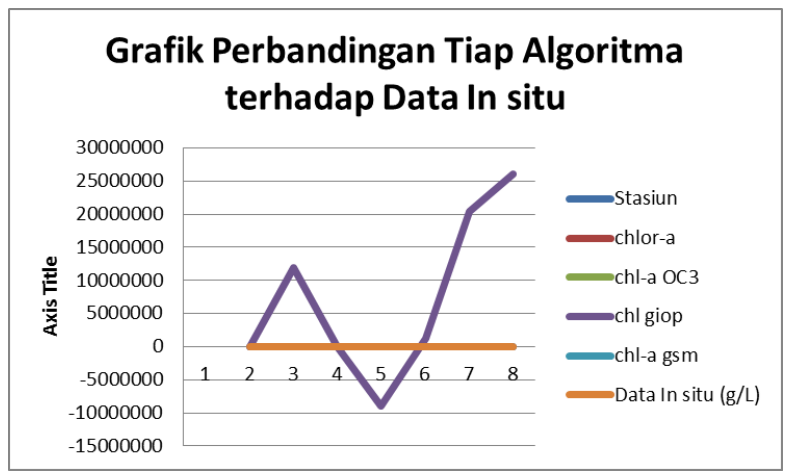

Gambar 5. Grafik Perbandingan antar Algoritma Chl-a terhadap Data In situ

Berikut adalah hasil dari perhitungan algoritma TSS terhadap data in situ

Tabel 7. Hasil Perhitungan Algoritma Chl-a terhadap Data In situ

Stasiun TSM clark Data In situ (g/L)

\begin{tabular}{rrr}
\hline 4 & $4,47 \mathrm{E}+23$ & 27 \\
14 & $1,21 \mathrm{E}+24$ & 8 \\
15 & $4,06 \mathrm{E}+28$ & 4 \\
\hline
\end{tabular}

(Sumber : Debby Marzella)

Grafik dari perbandingan hasil algoritma TSM Clark terhadap data in situ adalah sebagai berikut.

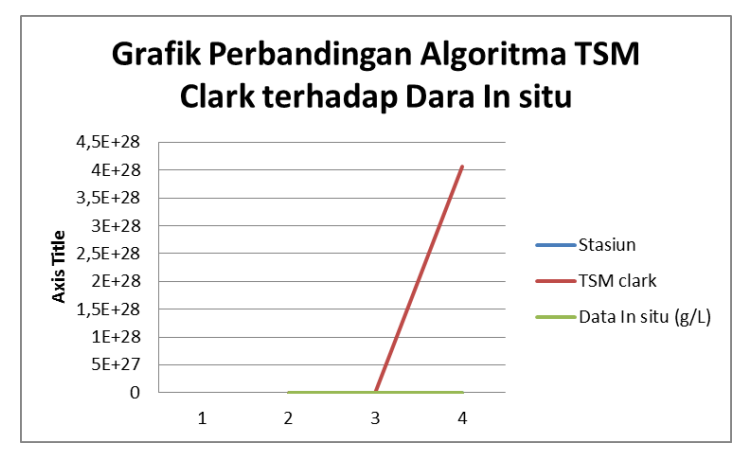

Gambar 6. Grafik Perbandingan antar Algoritma TSS terhadap Data In situ

\section{PENUTUP}

Algoritma Chl-a dan TSS yang tersedia pada perangkat lunak SeaDAS belum cukup baik untuk digunakan dalam perairan pesisir Indonesia.
Namun pemodelan algoritma yang didapat melalui pengukuran nilai spektral pada Perairan Pulau Poteran, cukup baik untuk mengestimasi nilai Chl-a. Sementara untuk pemodelan algoritma TSS tidak dapat digunakan untuk mengestimasi nilai TSS.

Dalam penelitian ini, perbedaan nilai yang didapat melalui perhitungan algoritma dengan data in situ dimungkinkan karena kesalahan laboratorium dalam hal pemberian satuan.

\section{UCAPAN TERIMAKASIH}

Penelitian ini didukung dan didanai oleh SIDI (Small Island Development Initiative) tim Pulau Poteran hasil kerjasama dari DAAD Jerman dan DIKTI serta didanai dan didukung oleh DIKTI dalam skema PKM (Program Kreativitas Mahasiswa)

\section{DAFTAR PUSTAKA}

Ambarwulan, W. 2002.Mapping of TSM concentrations from SPOT and Landsat TM satellite images for Integrated Coastal Zone Management in Teluk Banten, Indonesia. MSc Thesis, ITC, Enschede, Netherland.

Budhiman, S. 2004. Mapping TSM Concentrations from Multisensor Satellite Images in Turbid TropoicalCoastal Waters of Mahakam DeltaIndonesia, Master thesis, Netherland

Cahyono, B. (Universitas D. (2010). Proses Pengolahan Citra Modis Untuk Menduga Konsentrasi Klorofila Sebagai Indikator Tingkat Kesuburan di Perairan Utara Papua

Effendi, H. 2000.Telaah Kualitas Air Bagi Pengelolaan Sumberdaya dan Lingkungan Perairan. Bogor: Institut Pertanian Bogor

Fegie, I. N. (2013). Identifikasi Sebaran Sedimentasi dan Perubahan Garis Pantai Di Pesisir Muara Perancak-Bali Menggunakan Data Citra Satelit ALOS AVNIR-2 Dan SPOT-4

Hermawan, M. D., Sasmito, B., Hani'ah, I., Parwaty, D. E., \& Budhiman, S. (2012). Analisis Distribusi Total Suspended Matter dan Klorofil-A Menggunakan Citra Terra Modis Level 1B Resolusi 250 Meter dan 500 Meter

Jaelani dkk (2014). Pemetaan Distribusi Spasial Konsentrasi Klorofil-A dengan Landsat 8 di Danau Matano dan Danau Towuti, Sulawesi Selatan

Jaelani, L. M., Matsushita, B., Yang, W., \& Fukushima, T. (2013). Evaluation of four MERIS atmospheric correction algorithms in Lake Kasumigaura, 
Japan. International Journal of Remote Sensing, Japan: Tsukuba University

Kusuardini, A. 2011.Estimasi Konsentrasi Padatan Tersuspensi (TSS) dan Klorofil-A dari Citra MODIS Hubungannya dengan Marak Alga di Perairan Teluk Jakarta. Bogor : Institut Pertanian Bogor

Lestari, I. B. (2009). Pendugaan Konsentrasi Total Suspended Solid (TSS) dan Transparansi Perairan Teluk Jakarta Dengan Citra Satelit Landsat

NOAA.MODIS Spesification satellite MODIS (http://modis.gsfc.nasa.gov/about/spesification.p hp)

[Diakses pada : 12 Oktober 2014].

Nurjati, C., \& Handayani, H. H. (2011). Penginderaan Jauh Untuk Estimasi Kandungan TSS di Wilayah Pantai Timur Surabaya Akibat Pembuangan Lumpur Lapindo ., 5-16.

Parwati, E., (2014). Analisis Dinamika Fluktuasi TSS (Total Suspended Solid) Sepanjang DAS-Muara Laut Di Perairan Berau Kalimantan.
Parwati, E., Soewardi, K., \& Kusumastanto, T. (2011). Dampak Perubahan Kawasan Hutan Menjadi Areal Industri Batubara Terhadap Kualitas Air di Sepanjang DAS Berau Kalimantan Timur

Purba, M. E. K. (Universitas S. U. (2009). Analisa Kadas Total Suspended Solid (TSS)

Sulaiman, A., Hendiarti, N., Syamsudin, F., Frederik, M. C. G., Djajadihardja, Y. S., \& Andiastuti, R. (2005). Riset dan Teknologi Pemantauan Dinamika Laut Indonesia.

Surabaya, P. K. (2010). Laporan kegiatan pengendalian pencemaran kawasan pantai dan pesisir, 1-14.

Tarigan, M. S. 2008. Pemantauan Kualitas Perairan (Konsentrasi Klorofil-A) di Teluk Jakarta DenganMenggunakan Data Multi-Temporal Citra Satelit Terra MODIS. Jurnal Lingkungan Tropis 